\title{
Organisational Culture and Workplace Corruption in Government Hospitals
}

\author{
Ma. Regina M. Hechanova, ${ }^{1}$ Isabel Melgar, ${ }^{1}$ Patrick Z. Falguera, ${ }^{2}$ and Mario Villaverde ${ }^{2}$ \\ ${ }^{1}$ School of Social Sciences, Ateneo de Manila University, Quezon City, Philippines \\ 2 School of Government, Ateneo de Manila University, Quezon City, Philippines
}

\begin{abstract}
$\mathrm{T}$ his study examines corruption attitudes and norms in government hospitals in the Philippines. It tests a culture-building model that advocates communication of desired values, leadership role modelling, employee role modelling, alignment of systems and structures, training and evaluation, and reinforcement. Results reveal components that influence corruption attitudes and norms. Communication predicted individual attitudes or acceptability of corrupt acts. Leadership, systems, and controls predicted the prevalence of corrupt acts. Employee role modelling predicted both acceptability of and the prevalence of corrupt acts. In addition, there is a positive relationship between individual attitudes and organisation norms reinforcing the dyadic relationship between the two.
\end{abstract}

Keywords: corruption, Philippines, organisation culture, integrity

Organisational integrity has increasingly become a critical barometer in the governance of institutions and countries. Country rankings and foreign investments have risen and fallen, based on the perception of how well they are able to show integrity in their systems and processes. Integrity has likewise become a criterion in quality accreditation of organisations. All these factors have given rise to increasing efforts to address corruption and ensure integrity in organisations.

There is a growing literature on how to address corruption. Most of this points to the importance of controls, policies, leadership, and norms. The latter, in particular, has been the most commonly cited cause of corruption (Huberts, 1998). Unfortunately, most of the articles on corruption have either been theoretical or qualitative in nature. This study seeks to fill this gap by providing quantitative evidence of the relationship of organisational culture with corruption attitudes and norms in the workplace.

\section{Workplace Corruption}

Corruption has often been described as either incidental, institutional, and systemic. Incidental corruption includes small-scale embezzlement and misappropriation, bribes, favouritism, and discrimination (Kpundeh, 1998). Institutional corruption involves bribery and kickbacks, collusion to defraud, large-scale embezzlement, misappropriation through public tender or disposal of pub- lic property, or economic privileges accorded to special interests (Kpundeh, 1998). Systemic corruption involves large-scale embezzlement through ghost workers on government payrolls, embezzling government funds through false procurement, large-scale disbursement of public property to special and privileged interests, and favours due to political contributions (Kpundeh, 1998).

Corruption leads to inefficient public expenditures, distortion of values, reduced government or organisational legitimacy, inappropriate technology acquisition, labour force inefficiencies, reduced competition, and money flight (Kindra \& Stapenhurst, 1998). Corruption has also been associated with poor quality of life, low economic levels, reduced economic growth and trade, and poor morale. Government corruption has been demonstrated to lower foreign investment (Globerman \& Shapiro, 2003), increase risk and uncertainty (Getz \& Volkema, 2001), and is said to be the reason why developing countries fail to prosper (Knack \& Keefer, 1995).

\section{Corruption in the Philippines}

Corruption has long been recognised as a problem in the Philippines. As early as the 1930s, the penal code articulated punishment for corrupt acts. The Anti-Graft and Corruption Practices Act was passed in the 1960s. Principles of accountability, constitutional independence, fiscal autonomy and disclosure of information were also

Address for correspondence: Ma. Regina M. Hechanova, Department of Psychology, Ateneo de Manila University, Quezon City, Philippines. Email: rhechanova@ateneo.edu 
enshrined in the 1987 Philippine constitution. In addition to laws, the country's Medium-Term Philippine Development Plan (MTPDP) targets the eradication of graft and corruption (Transparency International, 2006). The government has also established the National Anticorruption Plan of Action and its secretariat, which has created an anti-corruption road map coordinating all reform initiatives. The Lifestyle Check Coalition, a pool of government agencies and non-government organisations (NGOs), was created to investigate the morality and lifestyle of government officials. The budget of the Office of the Ombudsman has been increased in order to build investigative and prosecutorial capacity (Transparency International, 2006). Another anti-corruption intervention is the use of Integrity Circles, which are interest groups within an organisation that identify corrupt practices, analyse their causes and suggest organisation efforts to curb corruption (Arce, 2001). The recent years have also seen a rise in anti-corruption programs, including the Integrity Initiative by the private sector, a multi-sectoral group called Coalition against Corruption, the Judicial Reform Initiative by the Department of Justice, the Integrity for Investments project of the USAID, and the Integrity Management Program by the Office of the President, to name a few (Integrity Initiative, n.d.). There are so many laws and investigative bodies that have since been created to combat corruption in the country that the Philippines is said to be the country with the most anti-corruption measures in Asia (Quah, 2011).

Despite these initiatives, the Philippines only ranks 129th out of 182 countries, with a Corruption Perception Index (CPI) of 2.6 (Transparency International, 2011). Moreover, the Philippines has lost vast amounts of money to corruption. The United States Agency for International Development estimates that the losses amount to at least $20 \%$ of the annual national budget (Committee for the Evangelization of Culture, 2002). Corruption has also been cited as hampering the ability of foreign aid to deliver improvements in the country (de Guzman \& Montiel, 2012).

A report by Transparency International (2006) on National Integrity Systems in the Philippines reveals some reasons why corruption remains rampant in the country. The report pointed to the under-regulation of the whistleblower protection for government and the lack of coverage for the private sector. It highlighted weaknesses in information retrieval systems, political party systems, and independence of oversight bodies. It identified overregulation in certain areas, such as allowing politicians to become involved in appointment systems, and excessive power of the executive branch. The report proposed several recommendations, including the need to review laws on the appointment process, political financing, disclosure of information, and protection of whistleblowers. It also recommended the rationalisation and streamlining of government bureaucracy in order to raise wages of those in government. It pointed to the need to improve enforcement and the investigatory and prosecution ability of law enforcement agencies. Beyond these, capacity building was also identified as an important strategy to instill greater transparency, accountability and ethical behaviour. This includes strengthening leadership capability so that government institutions can continue to operate efficiently in the light of frequent changes in leaders. Finally, but perhaps most relevant to this study, it highlighted the need for research to inform anti-corruption legislation and efforts (Transparency International, 2006).

\section{Culture and Corruption}

Why does corruption occur? In a study on the perceived causes of corruption in the public sector, experts were unanimous that the three most important causes of corruption are norms and values of politicians and public servants, lack of control, and interrelationships between business, politics, and state. Of these, values and norms was the most commonly cited cause of corruption (Huberts, 1998).

This study focuses on organisation culture, which has been defined as a set of shared assumptions, values, and norms that guide employees' behaviour within an organisation (Schein, 2004). Assumptions are beliefs employees have about the organisation and its relationship to its environment. These beliefs guide and direct employee thoughts and behaviours. Values describe employees' shared ideals about work outcomes and behaviours. Values guide how employees act and these actions become shared norms of behaviours (Campbell \& Goritz, 2014).

There is a dyadic relationship between individuals and the organisation. Individual beliefs and values can shape organisational culture. At the same time, organisational norms and values can shape individual beliefs, values, and behaviours. Ashforth and Anand (2003) proposed that the normalisation of corruption in organisations has three pillars: institutionalisation, rationalisation and socialisation. Although corrupt behaviours can remain as individual behaviours, once a corrupt act produces positive outcomes it becomes included in organisational memory and is likely to be repeated. Past decisions and acts are assumed to be rational and become precedents. This results in the institutionalisation of corruption, where personal behaviours become impersonal norms, and idiosyncratic acts become shared procedures. These now form the nexus of an organisation's culture with regards to corruption (Ashforth \& Anand, 2003).

Rationalisation is the process by which individuals legitimise the acts. Corrupt individuals do not view themselves as corrupt. In fact, they continue to value fairness, honesty and integrity even as they engage in corruption. Rather, they rationalise why the specific behaviours are justifiable or excusable exceptions to normative rules. This is done through rationalisation mechanisms such as depersonalisation (victims are viewed as objects or lesser species), selective weighting ('we are not so bad'), 
appeal to higher loyalties (the end justifies the means), and metaphor of the ledger (good works are used to offset corrupt acts; Ashforth \& Anand, 2003).

Socialisation is the process by which newcomers are taught to perform and accept the corrupt practices. Ashforth and Anand (2003) explain that this can happen via three routes: co-optation, incrementalism, and compromise. In co-optation, newcomers may initially be induced to engage in small acts by rewards. This is sometimes a subtle process, and individuals may not even realise how the rewards may activate personal goals and biases. For example, accepting legitimate gifts from suppliers may predispose a buyer to favour that particular supplier. In terms of incrementalism, the 'foot-in-the-door' phenomenon suggests that small and seemingly innocuous decisions and acts may lead to greater acts. For example, newcomers may initially be induced to engage in small acts that may seem harmless. These small acts may initially create cognitive dissonance. However, the rationalisation strategies described previously will cause them to realign their attitudes, which may facilitate an escalation of behaviour. Each escalation causes desensitisation that may lead to greater readiness to partake in more corruption. The third avenue is compromise. Essentially, this means that individuals may be led to corruption because of attempts to resolve dilemmas, role conflicts and other problems. For example, politicians accrue power by cutting deals or currying favours (Ashforth \& Anand, 2003).

According to Ashforth and Anand (2003), these three routes may cause individuals to be seduced into corruption without even realising their actions are illegal or unethical. By the time individuals realise it, they may find it difficult to halt the behaviour without suffering psychological, social, financial, and legal costs. The temptation to cover up one's misdeeds may be so overwhelming that what used to be inadvertent becomes deliberate. Thus, certain corporate cultures can promote corrupt practices that may end up being termed as systematic or structural malfeasance (Luo, 2004).

\section{Building Organisational Culture}

Because culture is a critical part of ensuring integrity in organisations, it is important to shape it. Although there are no theories specifically describing how a culture of integrity is built, there are models of culture building. This study aimed to test a particular culture-building model by the Ateneo Center for Organisation Research and Development (Hechanova, 2014). The CREATE model describes six components necessary to shape organisational culture - Communication of desired values, Role modelling of leaders, Engagement of employees in culture building, Alignments of systems and structures to desired values, Training and development, and Evaluation and reinforcement of culture-consistent behaviours. Communication of values refers to the extent to which an organisation articulates the values and standards it wishes its employees to uphold. Role modelling is the extent leaders demonstrate and show support for the desired values. Employee engagement in culture building is the extent to which employees model and support the desired values. Alignment of systems, structures and controls is the extent to which the structures, systems and controls encourage the manifestation of desired values. Evaluation and reinforcement has to do with whether individuals are measured against and are rewarded or punished based on desired values. The CREATE model was developed based on case studies with Philippine organisations, but has never been used specifically for a culture of integrity. However, there is some support for each of its elements.

There is much agreement that communication of values and standards is important in enabling a culture of integrity. Reviews have shown that the majority of studies support the idea that the existence of a code of ethics is positively related to ethical decision making and raising awareness of ethical issues (Ford \& Richardson, 1994; Loe, Ferrell, \& Mansfield, 2000; O'Fallon \& Butterfield, 2005). Although some contend that employees need to be familiar with the specific contents and intentions of the code (Wotruba, Chonko, \& Loe, 2001), others have found that the mere presence of a code of conduct can have an impact even when people cannot remember the specific contents (Adams, Tashchian, \& Shore, 2001). Thus, it is important to socialise members and provide ethics training in order to provide the transition from theory to practice. It has been suggested that culture training should be able to impart not just the organisation's values but also the traits of character, moral virtue and responsible self-direction (Kalantari, 2010).

Implementation of rules is also a crucial aspect of culture building. Campbell and Goritz (2014) found that even when organisations have a code of conduct, employees do not take them seriously if it is not enforced and there are no consequences for non-compliance.

Leaders also play a critical role in the institutionalisation of corruption. Leaders dictate the type of ethical decision-making throughout the organisation and serve as role models and sources of behavioural guidance for employees (Brown \& Treviño, 2006). Ashforth and Anand (2003) suggest that leaders do not have to actually engage in corrupt behaviour to serve as role models. By rewarding, facilitating, authorising, condoning, ignoring or not being aware of corruption, they send a message to employees of what is acceptable behaviour.

Other than taking cues from their leaders, individuals may take cues from their peers. A qualitative study on corrupt organisations reports that individuals feel pressure from their peers. This pressure comes from two values security and team spirit. Employees turn a blind eye or even cooperate with those engaged in corruption because they are afraid to risk losing their job. At the same time, team spirit may reinforce the need to stick together, which in turn increases group coercion to maintain corruption norms (Campbell \& Goritz, 2014). 
Another important strategy against corruption is to align organisational structures, systems and controls to support integrity. For example, having transparent processes make it easier to catch and prevent corrupt behaviour. It has also been suggested that having a clear grievance procedure, providing protection for whistleblowers, and having a structure to investigate complaints of corrupt behaviours are but some ways to ensure a culture of integrity (Kalantari, 2010).

Unfortunately, much of the literature on corruption is theoretical or utilises qualitative data. To fill this gap, we tested the CREATE model quantitatively and examined the extent to which these culture-building dimensions predict individual attitudes and organisational culture with regards to corruption. Specifically, we hypothesised that:

Hypothesis 1: Communication of values and standards, leadership role modelling, employee modelling, systems and structures, training and evaluation are negatively correlated to acceptability of corrupt practices.

Hypothesis 2: Communication of values and standards, leadership role modelling, employee modelling, systems and structures, training and evaluation are negatively correlated to perceived prevalence of corrupt practices in the organisation.

Finally, given the dyadic nature of individual values and norms, we suggest a positive relationship between the two and predict that:

Hypothesis 3: There will be positive relationship between the hacceptability of corrupt practices and perceived prevalence of corrupt practices.

\section{Methodology}

\section{Setting}

In order to control for nuances in national culture and industry, this study focused on the healthcare industry in the Philippines. In a developing country such as the Philippines, health is an important concern. Unfortunately, the Philippine government spends only $1.2 \%$ of its GDP on health care, based on the Philippine National Health Account of 2011 (National Statistical Coordination Board, 2013). This is perhaps why government health facilities such as rural health units and village health stations are generally perceived to provide low-quality health services. A report by the Asian Development Bank (2007) cited problems such as poor diagnosis, repeat visits, unavailable or inferior medicines and supplies, lack of health professionals, long waiting times, inconvenient schedules, and rundown facilities. Another study by the Asian Institute of Management reported that corruption and fraud in health care further compounds the health inequity in the country (Hartigan-Go, Valera, \& Visperas, 2013).

\section{Design}

This study utilised a mixed-method, sequential exploratory design. In the first phase, interviews and secondary data were used to validate the framework and elicit beliefs, values and norms related to corruption. In the second phase, surveys were administered to test the hypotheses of the study.

\section{Phase One}

Participants. Twelve key informants from four hospitals were interviewed in this phase. There were three key informants from each hospital, consisting of a representative from management, medical and non-medical personnel.

Interviews and data analysis. Semi-structured interviews were conducted to elicit the respondents' definitions of corruption, examples of corrupt acts and perceived causes of corruption. Axial coding was conducted to elicit the beliefs, values and norms. Three researchers read the transcription of the interviews and identifed the themes individually before these were calibrated. These themes were then translated into survey items. Results of the interview suggested the validity of the CREATE model. In addition, the interviews also revealed the corrupt practices that exist in the healthcare industry.

\section{Phase Two}

Participants. A survey was created, pilot-tested and administered to a total of 357 individuals representing eight public hospitals. Given the sensitive nature of the topic, social desirability was controlled for by administering the short version of Marlowe-Crowne Social Desirability Scale (Leite, 2005). Based on norms from previous studies, those with a score of 7 and above were eliminated from the sample (Fischer \& Fick, 1993). A total of seven respondents were dropped, bringing the final sample to 350 .

The majority $(71 \%)$ of participants were female and married (65\%), with an average age of 42 years; $34 \%$ were administrative staff, $26 \%$ represented allied health professionals, $23 \%$ were nurses and $17 \%$ were doctors. One third (30\%) were rank and file employees, $29 \%$ were professional and technical employees and $41 \%$ were supervisory/managerial employees.

\section{Measures}

Acceptability of corrupt practices. Employee attitudes were measured in terms of whether or not employees view corrupt practices as acceptable. Thirty-three practices culled from the key informant interviews were included in a scale, including accepting commissions for purchase of equipment, accepting payments without receipts, and so on. Items utilised a 5-point Likert scale, with the higher the score indicating greater the acceptance of corrupt practices $(\alpha=.94)$.

Perceived organisation norms on corruption. This was defined as the extent to which employees' perceived corruption occurred inside their organisation. It was based on the 33 actions identified in the first phase of the study. Respondents were asked to indicate the extent to which they perceived these as being done in their organisation 


\begin{tabular}{|c|c|c|c|}
\hline & $\begin{array}{l}\text { Leadership, systems } \\
\text { and reinforcement }\end{array}$ & $\begin{array}{l}\text { Communication of } \\
\text { values and standards }\end{array}$ & $\begin{array}{l}\text { Employee } \\
\text { norms }\end{array}$ \\
\hline The hospital takes action based on the results of investigation & .766 & & \\
\hline People who are dishonest are punished here & .757 & & \\
\hline Policies on transparency and corruption are consistently implemented & .742 & & \\
\hline The hospital recognises honest behavior & .727 & & \\
\hline People who are dishonest are fired in this hospital & .715 & & \\
\hline There are controls in place to prevent corruption in this hospital & .712 & & \\
\hline The hospital consider an individual's integrity in promotion decisions & .707 & & \\
\hline The hospital has a process for investigating ethics complaints. & .700 & & \\
\hline People who are dishonest are reprimanded & .696 & & \\
\hline Our hospital leaders set a good example of honesty & .583 & & \\
\hline Our hospital leaders are consistent in implementing our code of conduct & .551 & & \\
\hline Our hospital provide seminars on value formation & .510 & .471 & \\
\hline We have a code of conduct in this hospital & & .804 & \\
\hline I am aware of the provisions in our code of conduct & & .723 & \\
\hline This hospital has identified integrity as one of its values & & .684 & \\
\hline Integrity is important in this hospital & & .604 & \\
\hline My co-workers will support me if I report dishonest behaviors & & & .793 \\
\hline My co-workers are likely to report dishonest behaviors & & & .715 \\
\hline My co-workers set a good example of integrity & & & .704 \\
\hline
\end{tabular}

on a 5-point Likert scale. The higher the score, the greater the perceived corruption in the organisation $(\alpha=.94)$.

Organisation culture dimensions. Initially, items representing the six factors of the CREATE model were measured in the survey instrument. The items were rated using a 5-point scale in which respondents assessed a stated trait or practice from 1 (not at all my company) to 5 (exactly like my company). Negatively stated items were reverse-scored so that higher scores indicated a positive culture.

To test for construct validity and common method variance, the Harman One Test was conducted with all the items used to measure the CREATE model. Items that had commonalities below .50 as well as double-loaded on multiple factors were dropped. Principal component analysis using Varimax rotation revealed only three unique dimensions among the predictor variables and these were used in the final analysis (see Table 1).

Communication of values and standards is the extent to which the organisation identified integrity as a value and articulated a code of ethics. It was measured using four items that include 'This hospital has identified integrity as one of its values' and 'I am aware of the provisions in our code of conduct' $(\alpha=.94)$.

Leadership role modelling, systems and controls describe the extent to which leaders role model integrity ('Our hospital leaders set a good example of honesty') and allow it to happen ('Our hospital leaders condone corrupt behaviour'). It also includes the presence of systems to control corruption ('The hospital has a process for investigating ethics complaints'), train people on values ('Our hospital provide seminars on value formation'), reward honesty ('The hospital recognises honest behaviour') and sanction corrupt acts ('People who are dishonest are fired in this hospital'). It was measured using 12 items ( $\alpha=$ $.93)$.
Employee modelling describes the extent to which respondents perceive their peers are honest ('My co-workers set a good example of integrity'), are likely to act or support actions against corruption ('My co-workers are likely to report dishonest behaviours'). It was measured using three items $(\alpha=.73)$.

\section{Results \\ Descriptive Statistics}

The mean scores show that among the three organisational culture dimensions, communication of values and standards had the highest score $(M=4.18, S D=.63)$. This suggests that most government hospitals do articulate the value of integrity and have a code of conduct. The next highest rated $(M=3.70, S D=.69)$ was leadership, systems and controls. This suggests that government hospitals do have systems, sanctions and rewards related to integrity. The lowest rated organisational culture dimension was employee modelling. This also had the largest range $(M=$ $3.61, S D=.74)$, suggesting mixed opinions on the extent to which co-workers are perceived to consistently manifest integrity.

Acceptability of corrupt acts received low ratings $(M=1.56, S D=.57)$, revealing that most employees view corrupt acts an undesirable. Perceived presence of corrupt act was likewise low $(M=1.55, S D=.72)$, suggesting that the corrupt behaviours are not commonly observed by respondents. However, the larger standard deviation suggests mixed opinions.

\section{Communication of Values and Standards and Corruption}

We found support for our hypothesis that communication of values and standards is negatively correlated to acceptability of corrupt practices and prevalence of 
Table 2

Correlations and Descriptive Statistics

\begin{tabular}{llllllll}
\hline & Mean & $S D$ & 1 & 2 & 3 & 4 & 5 \\
\hline 1. Leadership, systems and reinforcement & 3.70 & .69 & $(.93)$ & & & & \\
2. Communication of values and standards & 4.18 & .63 & $.55^{* *}$ & $(.75)$ & & & \\
3. Employee modelling & 3.61 & .74 & $.54^{* *}$ & $.44^{* *}$ & $(.72)$ & & \\
4. Acceptability of corrupt practices & 1.57 & .52 & $-.20^{* *}$ & $-.29^{* *}$ & $-.26^{* *}$ & $(.94)$ & \\
5. Perceived presence of corrupt practices & 1.55 & .72 & $-.58^{* *}$ & $-.32^{* *}$ & $-.40^{* *}$ & $.26^{* *}$ & $(.98)$ \\
\hline
\end{tabular}

Note: Cronbach alpha reliability ${ }^{* *}$ significant at $p>.01$.

\section{Table 3}

Regression Analysis

\begin{tabular}{|c|c|c|c|c|c|c|c|c|}
\hline & \multicolumn{4}{|c|}{ Acceptability of corrupt practices } & \multicolumn{4}{|c|}{ Perceived organisation norms Corrupt practices } \\
\hline & B & $S E$ & $\beta$ & $t$ & B & $S E$ & $\beta$ & $t$ \\
\hline Leadership, systems and reinforcement & .01 & .05 & .02 & .22 & -.58 & .06 & -.55 & $9.58 * *$ \\
\hline Communication of values and standards & -.18 & .05 & -.22 & $-3.53^{* *}$ & .06 & .06 & .05 & .92 \\
\hline \multirow[t]{2}{*}{ Employee norms } & -.12 & .04 & -.17 & $-2.77^{* *}$ & -.13 & .05 & -.13 & $-2.49^{* *}$ \\
\hline & \multicolumn{4}{|c|}{$F(3,350)=13.59, p<01, R^{2}=.10$} & \multicolumn{4}{|c|}{$F(3,340)=62.76, p<01, R^{2}=36$} \\
\hline
\end{tabular}

corrupt practices in the organisation. As shown in Table 2, the correlations of communication of values and standard with acceptability was negative $(r=-.29, p<.05)$. At the same time, communication was negatively correlated to prevalence of corrupt practices $(r=-.32, p<.05)$. When taken together with the other factors in a regression analysis, communication predicted acceptability of corrupt acts $(\beta=-.22, t=3.53, p<.05)$. However, communication of values did not predict prevalence of corrupt practices (Table 3).

\section{Leadership, Systems, Controls and Corruption}

The hypothesis that leadership, systems and controls is negatively correlated to acceptability of corrupt practices and reported incidence of corrupt practices in the organisation was likewise supported. As seen in Table 2, the correlations of leadership, systems and controls with acceptability of corrupt acts was negative $(r=-.20, p<$ .-05). At the same time, leadership, systems and controls were also negatively correlated with prevalence of corrupt practices $(r=-.58, p<.05)$. Regression analysis revealed that when taken with the other culture building dimensions, leadership, systems and controls predicted the presence of corrupt practices $(\beta=-.55, t=9.58, p<.05)$ but not acceptability of corrupt practices.

\section{Employee Modelling and Corruption}

We also found support for our hypothesis that employee modelling would be negatively correlated to both acceptability $(r=-.26, p<-.05)$ and presence of corrupt practices $(r=-.40, p<.-05)$. Regression analysis revealed that employee modelling predicted both acceptability $(\beta=-.17, t=2.77, p<.05)$ and prevalence of corrupt practices $(\beta=-.13, t=2.49, p<.05)$.

\section{Corruption Attitudes and Norms}

Our final hypothesis was that there would be a dyadic relationship between attitudes and norms. As hypothesised, acceptability and prevalence of corrupt acts was positively correlated $(r=-.26, p<-.05)$.

\section{Discussion}

The study examined the relationship between culturebuilding dimensions and their relationship with workplace culture of corruption. Of the six factors in the CREATE framework, the dimensions communication of values and standards and employee modelling were validated. However, instead of falling into separate dimensions, items measuring leadership behaviour and systems and controls constituted only one factor. One interpretation of this is that leaders play a critical role in creating and implementing systems and structures. As suggested by Ashforth and Anand (2003), beyond role modelling, leaders play a critical role in the institutionalisation of corruption. The results suggest that, at least in this sample, the effectiveness of systems and structures rely heavily on leaders. Thus, it is important that leaders know what is happening on the ground. Leaders influence the prevalence of corrupt acts by being unaware of how systems and structures function, and by rewarding, facilitating, authorising, condoning or ignoring corruption.

All three organisational dimension factors were correlated to corruption attitudes. However, when taken together, not all of them predicted both corruption attitudes and norms. Communicating the value of integrity predicted acceptability of corrupt acts. This reinforces previous literature that it is important for organisations to clearly articulate the value of integrity and make explicit expected standards of behaviours through a Code of Conduct/Ethics. As suggested by other researchers, the existence of a code of ethics is positively related to ethical 
decision making and raising awareness of ethical issues (Ford \& Richardson, 1994; Loe et al., 2000; O'Fallon \& Butterfield, 2005). There is evidence that even if people cannot remember what is in it, just the presence of a code can have an impact on corrupt behaviour (Adams et al., 2001).

Leadership role modelling, controls, and systems for rewards and training predicted the perceived presence of corrupt acts. This validates the importance of organisational structures, such as an anti-corruption committee, transparency in record keeping and information, systems for control and protection of whistle-blowers, punishment of transgressors, and rewards for honest behaviour (Luo, 2004). It also reinforces the value of having leaders who not only articulate the value of integrity but also manifest it in their actions. This suggests that visibility of leaders is important as they provide employees with cues on what behaviours are desired and acceptable.

The finding that communication of values and employee norms shape attitudes but that it is leadership and controls that influence behaviour is noteworthy because Ajzen's (1991) theory of planned behaviour does not differentiate the impact of norms and controls on attitudes and intent. However, the results validate the findings of Rabl (2011), whose model of corrupt action (Rabl \& Kuhlmann, 2008) makes a distinction between desire and volition. His model modified and extended Ajzen's theory and proposed that the strength of desire to commit corrupt acts depends on the actor's attitudes as well as subjective norms. Desire shapes intent that influences action. However, the strength of intent is also influenced by a number of factors, including the level of risk, expected penalties, and transaction costs. The results suggest that communicating norms and expectations, leadership role modelling, and systems and controls are all important, but they shape workplace integrity in different ways.

In addition to differentiating the impact of norms and controls, the study makes a valuable contribution by highlighting the importance of peers in shaping a culture of integrity. Results show that positive role modelling and support for anti-corruption initiatives predict both attitudes and behaviours. That employee norms predicted both acceptability and norms is especially noteworthy and may reflect the Philippines' collectivist culture. In such a culture, peers have a strong influence on identity and behaviour (Triandis, 2001). This is perhaps even more important in government organisations whose leaders may keep changing and thus may not have permanent influence on culture. As the result suggests, peers, and not just leaders, influence corruption norms.

It has been suggested that Philippine cultural norms such as utang na loob (debt of gratitude) and pakikisama (conformity to group) may aggravate the practice of corruption (Montiel, 2000). Given this, the results imply that in order to build a culture of integrity, interventions need to engage employees in culture-building efforts. Initiatives such as integrity circles or employee groups that identify corrupt practices, analyse their causes and suggest organisational efforts to curb corruption may be an important anti-corruption initiative. Unfortunately, there is a lack of evaluation on the actual impact of these programs (Arce, 2001).

Beyond creating mechanisms to involve employees in anti-corruption or integrity initiatives, it may also be important to identify informal leaders who can serve as role models, culture bearers and change agents. Their support for changes in policies will be important in ensuring the acceptance of and smooth implementation of integrity initiatives. In addition, in Philippine government institutions, new leaders often bring with them key staff or managers who are typically coterminous with the executives. Government leaders who wish to enable reform need to make sure that their key managers and staff champion and model integrity.

\section{Limitations and Implications for Future Research}

Organisational culture as an object of study is difficult because of the fluid nature of organisations. One limitation of this study was its cross-sectional design. Future studies that are longitudinal in nature and utilise pre-post designs may provide more robust evidence on the impact of culture-building dimensions.

The subject of corruption is also a sensitive one. Although we attempted to address the issue of social desirability by measuring it, other researchers may wish to consider utilising other unobtrusive and objective measures of corruption, such as observation, reports, and so forth.

The study focused on obtaining quantitative data. Future studies may wish to deepen understanding of how these factors shape corruption attitudes and behaviours. In addition, more data on barriers and drivers to corruption in the government hospitals may be useful in understanding the kind of interventions necessary to build a culture of integrity.

The study was limited to one industry in the Philippines. Future researches may wish to validate these three factors that shape organisational culture of integrity in other industries and cultural contexts.

Liu and Bernardo (2014) point out that psychology research today is dominated by nomothetic science and experimental studies, and practical concerns and field studies appear to be taking a back seat. They challenge other psychologists to engage stakeholders in the process of action research with the end outcome of enabling social change. Thus, an even greater challenge would be to utilise the findings in order to effect change. Following the scientist-practitioner model, future researchers may be able to identify what interventions actually have an impact on eradicating corruption and building a culture of integrity. 


\section{Conclusion}

Limitations notwithstanding, this study provides quantitative evidence of the role of culture-building dimensions in predicting corruption attitudes and norms. Specifically, the results suggest that organisations that wish to build a culture of integrity need to clearly articulate integrity as a value. In addition, standards for behaviour through codes of conduct or policies on disbursement (e.g., gifts) are important in clarifying what is acceptable and unacceptable behaviour. At the same time, role modelling of leaders and integrity systems and structures are important in shaping norms. Finally, the study highlights the importance of engaging employees in the process of culture building. As the results show, peers influence both attitudes and norms, making them an important resource in shaping a culture of integrity.

\section{Acknowledgments}

This study was funded by a Ateneo de Manila University Research Council grant.

\section{References}

Adams, J.S., Tashchian, A., \& Shore, T.H. (2001). Code of Ethics as Signal of Ethical Behavior. Journal of Business Ethics, 29, 199-211.

Ajzen, I. (1991). The theory of planned behavior. Organizational Behavior and Human Decision Processes, 50, 179-211.

Arce, W.F. (2001). Focusing on a values-and behavior based approach to counter corruption. An assessment of an Integrity Circles project. Quezon City, Philippines: Institute of Philippine Culture.

Ashforth, B., \& Anand, V. (2003). The normalization of corruption in organizations. Research in Organizational Behavior, $25,1-52$.

Asian Development Bank. (2007). Philippines: Critical development constraint (Country diagnostic studies). Manila: Asian Development Bank.

Brown, M.E., \& Treviño, L.K. (2006). Ethical leadership: A review and future directions. The Leadership Quarterly, 17(6), 595616.

Campbell, J.L., \& Goritz, A.D. (2014). Culture corrupts! A qualitative study of organization culture in corrupt organizations. Journal of Business Ethics, 120, 291-311.

Committee for the Evangelization of Culture. (2002). Crosssectoral study of corruption in the Philippines. Naga: Ateneo de Naga University.

De Guzman, J., \& Montiel, C. (2012). Social representations of foreign aid: Exploring meaning making in aid practice in Sulu, Southern Philippines. Journal of Pacific Rim Psychology, 6(1), 1-17.

Fischer, D., \& Fick, C. (1993) Measuring social desirability: Short forms of the Marlowe-Crowne Social Desirability Scale. Educational and Psychological Measurement, 53, 417-424.
Ford, R.C., \& Richardson, W.D. (1994). Ethical decision making: A review of the empirical literature. Journal of Business Ethics, 13(3), 205-221.

Getz, K.A., \& Volkema, R.J. (2001). Culture, perceived corruption, and economics: A model of predictors and outcomes. Business and Society, 40, 7-30.

Globerman, S., \& Shapiro, D. (2003). Governance infrastructure and US foreign direct investment. Journal of International Business Studies, 34, 19-39.

Hartigan-Ho, K., Valera, M.T., \& Visperas, M.K. (2013). Re-engineering of Philippine health care: Can We afford to muddle along? (AIM Working Paper Series, 13-012, 1-8). Retrieved February 21, 2014 from www.aim.edu/files/download/849

Hechanova, M.R. (2014). Organization development and innovation. In M.R. Hechanova, M.T. Calleja \& V. Villaluz (Eds). Understanding the Filipino Worker and Organization (pp. 209-224). Quezon City, Philippines: Ateneo University Press.

Huberts, L.W.J.C. (1998). What can be done against public corruption and fraud: Expert views on strategies to protect public integrity. Crime, Law \& Social Change, 29, 209-224

Integrity Initiative. (n.d). Anti-corruption programs in the Philippines. Retrieved July 29, 2014 from http://www. integrityinitiative.com/partner-projects

Kalantari, B. (2010). Corruption in public and private organizations: Causes, consequences and remedies. International Journal of Ethics, 6(4), 301-313.

Kindra, G.S., \& Stapenhurst, R. (1998). Social marketing strategies to fight corruption. Washington, DC: Economic Development Institute of the World Bank

Knack, S., \& Keefer, P. (1995). Institutions and economic performance: Cross-country tests using alternative institutional measures. Economics and Politics, 7, 207-227.

Kpundeh, S. (1998). Political will in fighting corruption. In S. Kpundeh \& I. Hors (Eds.), Corruption and integirty improvement initiatives in developing countries (pp. 91-110). New York, NY: United Nations Development Programme.

Leite, W. (2005). Validation of scores on the Marlowe-Crowne Social Desirability Scale and the balanced inventory of desirable responding. Educational and Psychological Measurement, 65(1), 140-154.

Liu, J.H., \& Bernardo, A.B.I. (2014). Social psychology for social change: Foundations for and introduction to a program of action-oriented research. Journal of Pacific Rim Psychology, $8(2), 29-34$.

Loe, T.W., Ferrell, L., \& Mansfield, P. (2000). A review of empirical studies assessing ethical decision making in business. Journal of Business Ethics, 25(3), 185-204.

Luo, Y. (2004). An organizational perspective of corruption. Management and Organization Review, 1(1), 119-154.

Montiel, C.J. (2000). Philippine political culture: A conceptual framework. Philippine Journal of Psychology, 33, 112128.

National Statistical Coordination Board (NSCB). (2013). 2011 Philippine National Health Accounts. Retrieved 
July 21, 2014, from http://www.nscb.gov.ph/stats/pnha/ publication/NSCB_PNHA\%202005-2011.pdf

O'Fallon, M.J., \& Butterfield, K.D. (2005). A review of the empirical ethical decision-making literature: 1996-2003. Journal of Business Ethics, 59(4), 375-413.

Quah, J.S.T. (2011). Curbing corruption in Asian countries: An impossible dream? Bingley, UK: Emerald Group Publishing.

Rabl, T., \& Kühlmann, T.M. (2008). Understanding corruption in organizations: Development and empirical assessment of an action model. Journal of Business Ethics, 82(2), 477-495.

Rabl, T. (2011). The impact of situational influences on corruption in organizations. Journal of Business Ethics, 100, 85-101.

Schein, E. (2004) Organizational climate and culture. In G.R. Goethals, G.J. Sorenson, \& J.M. Burns (Eds.),
Encyclopedia of leadership (vol. 3, pp. 1112-1117). Thousand Oaks, CA: Sage Reference.

Transparency International. (2011). Global corruption report 2011: Corruption in the private sector. Retrieved from http://www.transparency.org/publications/gcr

Transparency International. (2006). National integrity systems (Transparency International Country Study Report). Philippines: Author. Retrieved from http://www.transparency.org/ policy_research/nis/nis_reports_by_country

Triandis, H.C. (2001). Individual-Collectivism and Personality. Journal of Personality, 69 (6), 907-924.

Wotruba, T.R., Chonko, L.B., \& Loe, T.W. (2001). The impact of ethics code familiarity on manager behavior. Journal of Business Ethics, 33(1), 59-69. 